\author{
Batovsky Marian ${ }^{1 \star}$, Zamborsky Tomas ${ }^{1}$, \\ Radwan Khaled ${ }^{1}$, Desatova Barbora ${ }^{1}$ \\ and Kadleckova Barbora ${ }^{2}$ \\ ${ }^{1}$ Gastroenterological Clinic of Slovak Medical \\ University, Bratislava, Slovak Republic \\ ${ }^{2}$ Gastroenterological Center Thalion, Bratislava, \\ Slovak Republic \\ Dates: Received: 01 June, 2015; Accepted: 22 \\ June, 2015; Published: 26 June, 2015 \\ *Corresponding author: Marian Batovsky, \\ Gastroenterological Clinic of Slovak Medical

\section{Research Article \\ Beta-(1,3/1,6)-D-glucan Helps to Decrease Opportunistic Infections in Crohn's Disease Patients Treated with Biological Therapy} University Bratislava, Slovak Republic, E-mail: batovsky@pe.unb.sk

www.peertechz.com

ISSN: 2455-2283

Keywords: Crohn's disease; Beta-glucan; Clinical trial; Maintenance therapy

\section{Summary}

Background: Secondary intercurrent infections in patients with inflammatory bowel disease (IBD) represent a very important problem in daily clinical practice because of their significant contribution to quality of life and work ability. Beta-glucans are known to act as non-specific immunomodulators that exhibit an anti-inflammatory effect as evident in animal and human studies. Imunoglukan $\mathrm{P} 4 \mathrm{H}^{\circledR}$ capsules are nutritional supplement containing $100 \mathrm{mg}$ of beta-(1,3/1,6)-D-glucan pleuran isolated from oyster mushroom Pleurotus ostreatus and $100 \mathrm{mg}$ of vitamin C.

Aims: To evaluate the influence of Imunoglukan $\mathrm{P} 4 \mathrm{H}^{\circledast}$ (Pleuran, s.r.o., Slovakia) on the secondary morbidity added to biological therapy in maintaining remission of Crohn's disease (CD) for 12 months.

Patients and methods: A double-blinded, placebo-controlled, randomised bicentric study was carried out which included $53 \mathrm{CD}$ patients randomly divided into two groups treated with Imunoglukan $\mathrm{P} \mathrm{H}^{\circledast}$ (with beta-(1,3/1,6)-D-glucan pleuran from Pleurotus ostreatus and vitamin C) 1 capsule daily (23 patients) and placebo (vitamin C only) 1 capsule daily ( 30 patients) respectively. All patients also continued their biological maintenance therapy. Before inclusion the patients were required to: be consented (written), complete a standard quality of life questonnaire for patients with inflammatory bowel disease (SIBDQ), Crohn's disease activity index (CDAl) was evaluated, full blood count, standard biochemical tests - bilirubine (Bi), alaninaminotranspherase (ALT), aspartataminotranspherase (AST), alcaline phosphatase (ALP), gammaglutamyltranspeptidase (GMT), serum amylases (AMS), natrium $(\mathrm{Na})$, kalium $(\mathrm{K})$, C-reactive proteine (CRP) and faecal calprotectin were also performed. These tests and questionaires were repeated at 2-month intervals, at each time patients reported intercurrent diseases and their lengths. All data were recorded in patient protocol and statistical signification was tested by matching of two ratios with Yates correction and by Mann-Whitney test.

Results: From 53 included CD patients 39 reached the end of trial, 14 patients interrupted the study prematurely. Imunoglukan $\mathrm{P} 4 \mathrm{H}^{\circledast}$ was administered to 10 patients and placebo to 29 patients. $0 / 10$ patients in Imunoglukan $P 4 H^{\circledast}$ group $(I G)$ and $1 / 29$ patients in placebo group (PG) interrupted prematurely administration of preparation for intolerance and $1 / 10$ patients in IG and $2 / 29$ patients in $P G$ for relapsing of CD. These differences were not statistically significant ( $p=0,5519$ and 0,7508 resp.). At least one intercurrent infectious or allergic disease occurred in 6/10 of IG patients and in 25/29 of PG patients $(95 \% \mathrm{Cl}, \mathrm{p}=0,0384)$. In $4 / 10$ respectively $11 / 29$ of patients one intercurrent disease, in $2 / 10$ resp. $7 / 29$ of patients two, in $0 / 10$ resp. $5 / 29$ of patients three and in 0/10 resp. 2/29 of patients four diseases were reported. Imunoglukan $\mathrm{P}_{4} \mathrm{H}^{\circledast}$ also significantly decreased the number of intercurrent diseases compared to placebo in this study (95\% Cl, $p=0,0196)$. The treatment did not influence SIBDQ, CDAI, blood count and biochemical parameters tested.

Conclusion: Imunoglukan $\mathrm{P}_{4} \mathrm{H}^{\circledast}$ added to biological therapy in $\mathrm{CD}$ patients in remission has significantly reduced the secondary morbidity in comparison to placebo. This preparate was well tolerated, no adverse or undesirable effects were observed and the course of CD remission remained unchanged.

\section{Introduction}

Beta-glucans are polysaccharides that activate the immune cells of the intestinal mucosa. They are characterized by their antiinflammatory activity in the animal experiments as well as in patients with inflammatory bowel disease (IBD). The formula Imunoglukan $\mathrm{P}_{4} \mathrm{H}^{\circledR}$ is a nutritional supplement that contains a complex of biologically active polysaccharides of natural origin based on beta-
(1,3/1,6)-D-glucan pleuran isolated from oyster mushroom Pleurotus ostreatus. It acts as an immunomodulator, promoting innate and adaptive immunity of the organism. In addition to $100 \mathrm{mg}$ of pleuran Imunoglukan $\mathrm{P}_{4} \mathrm{H}^{\circledR}$ formulation contains $100 \mathrm{mg}$ of vitamin $\mathrm{C}$ as well.

\section{Aim of the Study}

To evaluate the influence of Imunoglukan $\mathrm{P} 4 \mathrm{H}^{\circledR}$ on the secondary 
morbidity (in terms of expected reduction in the number of infections) added to biological therapy in maintaining remission of Crohn's disease (CD) for 12 months.

\section{Patients and Methods}

Double-blind, randomized, placebo-controlled trial phase IV was carried out in two centers of biological therapy of IBD.

Enrolment of the patients in the study took place at both centers, including consecutive, randomly allocated patients over 18 years of age. Next inclusion criteria were Crohn's disease in clinical and laboratory remission on biological treatment with infliximab (IFX) or adalimumab (ADA) and signed informed consent.

The following patients should be considered non-eligible: patients with malignancy 6 months prior to enrolment, immunodeficiency with the substitution of immunoglobulins, severe or decompensated internal disease, exacerbation of acute infectious or allergic diseases 14 days prior to enrolment, history of organ transplantation, use of immunosuppressants, pregnancy and lactation.

First group of patients (23 patients) used 1 capsule of Imunoglukan $\mathrm{P} 4 \mathrm{H}^{\circledR}$ (100 mg of pleuran and $100 \mathrm{mg}$ of vitamin $\mathrm{C}$ in 1 capsule) daily and the second group (30 patients) used 1 capsule of placebo (100 mg of vitamin C) daily. Before enrolling into the study the patient:

1 / filled out a quality of life questionnaire for patients with inflammatory bowel disease / SIBDQ /,

\section{2 / had Crohn's Disease Activity Index /CDAI/ calculated}

3 / was tested for blood count, blood glucose, creatinine, total protein, albumin, Bi, AST, ALT, ALP, GGT, AMS, Na, K and CRP

4 / gave a stool sample for the determination of faecal calprotectin,

5 / the above steps from 1-4 were repeated at 2-month intervals, during which the patient reported the occurrence and duration of any intercurrent disease, as well as tolerance and occurrence of any adverse effects of the product Imunoglukan $\mathrm{P} 4 \mathrm{H}^{\circledR}$.

$6 /$ all observed data and parameters were recorded in the patient protocol,

7 / results were statistically evaluated by test for comparison of two proportions with Yates correction and Mann-Whitney test.

\section{Criteria for early exclusion from the study}

Following criteria for the early interruption of study were choosen:

1 / Crohn's disease relapse - decrease in the recorded SIBDQ score below 50, respectively increase in CDAI (over 150), CRP (over $10 \mathrm{mg} / \mathrm{l}$ ) and/or faecal calprotectin (over $300 \mathrm{ug} / \mathrm{ml}$ ) captured during one of the follow-ups every two months or a clinical deterioration with respect to Crohn's disease at any time.

2 / intolerance respectively occurrence of adverse events

3 / pregnancy

4 / breach of protocol

Criteria for evaluation of secondary morbidity were the occurrence of symptoms of intercurrent infectious disease for more than 6 days.

\section{Results}

The study included 53 patients, 39 of whom completed the clinical trial. 14 patients were prematurely withdrawn: one patient after one month because of placebo intolerance, three patients because of Crohn's disease relapse (after 2 respectively 8 months of using placebo, respectively after 3 months of using Imunoglukan $\mathrm{P} 4 \mathrm{H}^{\circledR}$ with the worsening of SIBDQ score, the rise of CRP and CDAI) and 10 patients were excluded because of failure to comply with the protocol.

Of the 39 evaluated patients (mean age 37 years, age range 2159 years) were 22 men (mean age 37 years, age range 21-59 years) and 17 women (mean age 36 years, age range 20-63 years). Thirteen patients were classified as $\mathrm{A} 2 \mathrm{~L} 3 \mathrm{~B} 3$, eight $\mathrm{A} 2 \mathrm{~L} 3 \mathrm{~B} 1$, four A2L1B2, three A2L1B1, two A2L3B2 and one patient A2L2B1, A2L2B2, A3L2B1, A1L3B3, A3L3B3, A3L3B2, A2L1B3, A3L1B2 and A1L1B1.

Ten patients were treated with ADA and 29 patients received IFX.

After unblinding the study, it was shown that 10 patients received Imunoglukan $\mathrm{P} 4 \mathrm{H}^{\circledR}$ and 29 patients were in the placebo group. 0/10 patients in the active group and $1 / 29$ patients in the placebo group discontinued the preparation because of intolerance. $1 / 10$ in the active group and $2 / 29$ patients in the placebo group were excluded from clinical trial because of Crohn's disease relapsing. Differences were not statistically significant ( $\mathrm{p}=0.5519$ respectively 0.7508$)$.

Before the start of the study, it was assumed that patients using Imunoglukan $\mathrm{P}_{4} \mathrm{H}^{\circledR}$ would have lower overall secondary morbidity compared with patients who received placebo. Another assumption was concerned about significantly lower occurrence of secondary morbidity in the second half of the trial, during which the beneficial immunological effect of Imunoglukan $\mathrm{P} \mathrm{H}^{\circledR}$ is ought to be fully develop. Differences in secondary morbidity were therefore recorded separately in the first and separately in the second half of the trial duration. Finally, the secondary morbidity was assessed throughout the study.

One intercurrent disease (bronchitis, eczema, viral, herpes simplex) occurred in three patients of the active group in the first half and in one patient in the second half of the study. Two diseases occurred in one patient in the first half and in another patient throughout the year of the trial (Table 1).

In the placebo group in the months 1-6 of the trial, 1-4 intercurrent diseases (bronchitis, viral infection, herpes simplex, eczema, sores,

Table 1: The occurrence of secondary morbidity in 10 Crohn's disease patients using Imunoglukan $\mathrm{P} 4 \mathrm{H}^{\circledR}$.

\begin{tabular}{|l|l|l|l|}
\hline Number of diseases & \multicolumn{2}{l|}{ Number of patients } & \\
\hline & months 1-6 & months 7-12 & months 1-12 \\
\hline One & 3 & 1 & 0 \\
\hline Two & 1 & 0 & 1 \\
\hline Three & 0 & 0 & 0 \\
\hline Four or more & 0 & 0 & 0 \\
\hline In total & 4 & 1 & 1 \\
\hline
\end{tabular}


Table 2: The occurrence of secondary morbidity in 29 Crohn's disease patients using placebo.

Number of diseases Number of patients

\begin{tabular}{|l|l|l|l|}
\hline & months 1-6 & months 7-12 & months 1-12 \\
\hline One & 8 & 1 & $\mathbf{2}$ \\
\hline Two & 6 & 1 & $\mathbf{0}$ \\
\hline Three & 4 & 0 & $\mathbf{1}$ \\
\hline Four or more & 0 & 0 & $\mathbf{2}$ \\
\hline In total & $\mathbf{1 8}$ & $\mathbf{2}$ & $\mathbf{5}$ \\
\hline
\end{tabular}

mycosis, hordeolum) occurred in 18 patients, and in the months 7-12 in two patients and the other 5 patients had secondary morbidity throughout the whole duration of the trial (months 1-12) (Table 2).

$6 / 10$ patients from the active group and 25/29 patients in the placebo group overcame at least one disease. Assumption of lower secondary morbidity in Imunoglukan $\mathrm{P} 4 \mathrm{H}^{\circledR}$ group was statistically confirmed. The proportion of patients who had at least one intercurrent disease was in the group receiving Imunoglukan $\mathrm{P} 4 \mathrm{H}^{\circledR}$ significantly lower than in the placebo group $(\mathrm{p}=0.384)$. Patients receiving Imunoglukan $\mathrm{P} 4 \mathrm{H}^{\circledR}$ had significantly fewer intercurrent diseases than those taking placebo $(p=0.0196)$.

Statistically significant differences in the incidence of secondary morbidity among groups of patients receiving Imunoglukan $\mathrm{P} 4 \mathrm{H}^{\circledR}$ and placebo separately in the first or second half of the trial were not found ( $\mathrm{p}=0.4844$ respectively. 0.6246 ).

Imunoglukan $\mathrm{P} 4 \mathrm{H}^{\circledR}$ administration did not affect the observed hematological and biochemical parameters.

\section{Discussion}

The present study was designed as a pilot one to investigate the effectiveness of Imunoglukan $\mathrm{P} 4 \mathrm{H}^{\circledR}$ in reducing of secondary morbidity in adult patients with Crohn's disease in remission treated with biological therapy. Another article solving this problem was not found in available literature. For this reason only the general information about effects of beta-glucans by some other clinical entities are mentioned in the discussion.

\section{Mushrooms and immunomodulation}

Whereas pharmaceuticals prepared by extraction of medicinal plants constitute an important part of evidence-based medicine also in the western hemisphere, medicinal mushrooms are mainly used as dietary supplements often without a medical indication. Scientific investigations and case studies from Asian medicine show that fungi have a very promising pharmacological potential. For centuries, mushrooms have been used as food and medicine in different cultures. More recently, many bioactive compounds have been isolated from different types of mushrooms (Russula albonigra, Ganoderma lucidum, Pleurotus ostreatus). Among these, immunomodulators have gained much interest based on the increasing growth of the immunotherapy sector. Mushroom immunomodulators are classified under four categories based on their chemical nature as: lectins, terpenoids, proteins, and polysaccharides [1,2].

\section{The effects of beta-glucans in vitro and in animal studies}

Beta-glucans showed in vitro macrophage activation by $\mathrm{NO}$ production as well as splenocytes and thymocytes proliferation. Moreover, it also exhibited potent antioxidant activities [3]. The formation of neutrophil extracellular traps has been characterized as a novel antimicrobial host defense strategy of neutrophils besides phagocytosis and degranulation, which may lead to entrapment and subsequent immobilisation and/or killing of bacterial pathogens. Recent data underline the fact the feed additive beta-glucan is able to modulate neutrophil function [4].

In animal studies with common carps and diabetic rats the administration of a beta-glucan-enriched extract exerts a beneficial effect via its immunological, antioxidant and anti-inflammatory activities. In next animal experiment, chinese authors evaluated the effect of mushroom beta-glucans derived from solid culture of Ganoderma lucidum on tumor inhibition by examining size of the primary tumor and rate of metastasis in Lewis lung carcinoma bearing mice given oral administration of beta-glucans with radiation therapy. A previous results showed that beta-glucans enhanced NK cell-mediated cytotoxicity in mice without lung carcinoma bearing in advance. Furthermore, applications of beta-glucans in conjuction with radiation therapy were effective in controlling tumor growth, and rate of metastasis, life threatening and can potentially serve as protective factor for wounds and hair loss that resulted from overgrowth of primary tumor in Lewis lung carcinoma bearing mice [5].

\section{The effects of beta-glucans in human studies}

Beta-glucans have been shown to reduce glycaemic response in some studies. It is hypothesised that this reduction may be a function of its physical properties that delay gastric emptying. The aim of a small study (30 patients and 10 healthy subjects) was to investigate the impact of soluble dietary fiber on gastric emptying, postprandial glycaemic and insulin response in patients with type 2 diabetes. Isoenergetic liquid with $7.5 \mathrm{~g} / 500 \mathrm{~mL}$ of oat beta-glucan resulted in less output volume in the distal stomach $(\mathrm{p}<0,05)$, decreased postprandial glucose $(p=0,001)$ and insulin $(p=0,001)$ in diabetic patients in comparison to controls. Beta-glucan improved postprandial glycaemia which was related to slowing down gastric emptying [6,7], assessed the effect of barley beta-glucan of different molecular weights on changes in glycaemic response and gastric emptying on diet-induced-thermogenesis in 15 healthy volunteers. Following the baseline measurements, the probands were fed a soup containing highmolecular-weight beta-glucan, a soup containing low-molecularweight beta-glucan or a control soup with no beta-glucan. Dietinduced-thermogenesis was measured using indirect calorimetry. There were differences in total diet-induced -thermogenesis between the three test meals with the high-molecular-weight beta-glucan meal having the lowest diet-induced -thermogenesis. The study indicates that high-molecular-weight beta-glucan has the ability to delay gastric emptying due to increased viscosity resulting in a decreased glycaemic response and diet-induced-thermogenesis. In a placebo-controlled, double-blind, randomized, multicentric clinical trial the effect of brewer's yeast beta-(1,3/1,6)-D-glucan consumption on the number of common cold episodes in healthy subjects was investigated. 162 healthy participants with reccuring infections received $900 \mathrm{mg}$ of either placebo $(n=81)$ or a beta-glucan preparation $(n=81)$ per day over a course of 16 weeks. In the per protocol population beta-glucan reduced the symptomatic common cold infections by $25 \%(\mathrm{p}=0,125)$. Yeast beta-glucan preparation increased the body's potential to defend against ivading pathogens [8]. Serum 1,3-beta-D-glucan level can sensitively and specifically reflect the state of systemic mycotic- 
causing diseases. Detecting 1,3-beta-D-glucan level in tears is good for diagnosis and monitor value in the evaluation of fungal keratitis [9].

\section{Imunoglukan $\mathbf{P} 4 \mathrm{H}^{\circledR}$}

Imunoglukan $\mathrm{P} 4 \mathrm{H}^{\circledR}$ contains beta- $(1,3 / 1,6)$-D-glucan extracted from fruiting body of oyster mushroom Pleurotus ostreatus. Betaglucan was purified and hydrolysed to remove proteins, fiber, and fats [10]. In an animal study was evaluated the effect of Imunoglukan $\mathrm{P}_{4} \mathrm{H}^{\circledR}$ on prophylactic treatment of adjuvant arthritis with methotrexate in rats. Methotrexate and its combination with Imunoglukan $\mathrm{P} 4 \mathrm{H}^{\circledR}$ significantly inhibited the markers of both inflammation and arthritis, increased body mass of arthritic rats and decreased both the hind paw swelling and arthritis score [11]. In a double-blind, placebocontrolled, randomised, multicentre study was observed a group of 175 children with more than 5 respiratory infections that occurred during the 12 months prior to the beginning of the study. Children were randomized into an active group, treated with Imunoglukan $\mathrm{P} 4 \mathrm{H}^{\circledR}$ syrup or a placebo group. In the active group, $36 \%$ of the children did not suffer from any respiratory infections compared to $21 \%$ in the placebo group $(\mathrm{p}<0,05)$. Imunoglukan $\mathrm{P}_{4} \mathrm{H}^{\circledR}$ also significantly decreased the frequency of flu and flu-like diseases and the number of lower respiratory tract infections [12]. In the similar study with 50 athletes Imunoglukan $\mathrm{P} 4 \mathrm{H}^{\circledR}$ significantly reduced the incidence of upper respiratory tract infection symptoms, increased the number of circulating $\mathrm{NK}$ cells and phagocytosis process remained stable [13]. Imunoglukan $\mathrm{P} 4 \mathrm{H}^{\circledR}$ dietary supplementation for 2 months decreased the suppressed immune system responses (with no reduction of NK cell activity during the recovery period) induced by short-term high-intensity exercise in double-blind pilot study with 20 elite athletes [14].

\section{Inflammatory bowel diseases and opportunistic infections}

Biological therapy is a risk factor for infectious complications, particularly opportunistic infections. Because of TB screening, other bacterial (pneumococcus), viral (herpes viruses) or fungal infections are more commonly occurring. The risk of infection increases significantly in the case of combination therapy with corticosteroids or immunosuppressants. A combination of the two mentioned drugs increases the risk of infection to three folds.

SABER study determined among patients with autoimmune diseases in the USA whether the risk of non-viral opportunistic infections was increased among users of anti - tumour necrosis factor preparates (a-TNF) when compared to users of non-biological agents used for active disease. Within a cohort of 33324 a-TNF users were identified 80 opportunistic infections, the most common of which was pneumocystosis. In the combined cohort, crude rate of non-viral opportunistic infections was 2,7 vs 1,7 per 1000 person-years (aHR $1,6,95 \%$ CI 1,0 to 2,6) [15].

\section{Conclusion}

This is the first double-blind, placebo-controlled study in $\mathrm{CD}$ patients in remission treated with biological therapy that has addressed the preventive effect of Imunoglukan $\mathrm{P} 4 \mathrm{H}^{\circledR}$ on secondary morbidity. The first results of this pilot study are promising and these findings indicate that pleuran may serve as an effective nutritional supplement for $\mathrm{CD}$ patients and decrease of secondary morbidity.

\section{References}

1. Lindequist $U$ (2013) The merit of medicinal mushrooms from a pharmaceutical point of view. Int J Med Mushrooms 15: 517-523.

2. El Enshasi HA, Hatti-Kaul R (2013) Mushroom immunomodulators: unique molecules with unlimited applications. Trends Biotechnol 31: 668-677.

3. Nandi AK, Samanta S, Maity S, Sen IK, Khatua S, et al. Antioxidant and immunostimulant beta-glucan from edible mushroom Russula albonigra. Carbohydrate Polymers 99: 774-782.

4. Brogden G, Krimmling T, Adamek M, Naim HY, Steinhagen D, et al. (2014) The effect of beta-glucan on formation and functionality of neutrophil extracellular traps in carp. Developmental Comparative Immunol 44: 280285.

5. Chen SN, Chang CS, Hung MH, Chen S, Wang W, et al. ( 2014) The effect of mushroom beta-glucans from solid culture of ganoderma lucidum on inhibition of the primary tumor metastasis. Evid Based Complement Alternat Med 252171.

6. Yu K, Ke MY, Li WH, Zhang SQ, Fang XC (2014) The impact of soluble dietary fibre on gastric emptying, postprandial blood glucose and insulin in patients with type 2 diabetes. Asia Pacific J Clin Nutrition 23: 210-218.

7. Thondre PS, Shafat A, Clegg ME (2013) Molecular weight of barley betaglucan influences energy expenditure, gastric emptying and glycaemic response in human subjects. Br J Nutrition 110: 2173-2179.

8. Annegret Auinger, Linda Riede, Gordana Bothe, Regina Busch, Joerg Gruenwald (2013) Yeast 1,3-1,6-beta-glucan helps to maintain the body's defence against pathogens: a double-blind, randomized, placebo-controlled, multicentric study in healthy subjects. Eur J Nutrition 52: 1913-1918.

9. Liu KF, Liang T, He $\mathrm{H}$ et al. (2013) The diagnosis and monitor for fungal keratitis by detection of $(1,3)$-beta-glucan in tears. Chinese $\mathrm{J}$ Experiment Ophtalmol 31: 1065-1068

10. Bukhari SA, Anjum F, Shahid M, Parveen A, Rasool N, et al. (2014) Analytical characterisation of beta-glucan isolated from fruiting body of Pleurotus ostreatus. Compl Rendus Acad Bulgare Sci 67: 655-664.

11. Rovenský J, Stančíkova M, Svík K, Bauerová K, Jurčovičová J, et al. (2011) The effects of beta-glucan isolated from Pleurotus ostreatus on methotrexate treatment in rats with adjuvant arthritis. Rheumatol Int 507-511.

12. Jesenak M, Majtan J, Rennerova Z, Kyselovic J, Banovcin P, et al. (2013) Immunomodulatory effect of pleuran (beta-glucan from Pleurotus ostreatus) in children with reccurrent respiratory tract infections. Int Immunopharmacol 15: 395-399.

13. Bergendiova K, Tibenska E, Majtan J (2011) Pleuran (beta-glukan from Pleurotus ostreatus) supplementation, cellular immune response and respiratory tract infections in athletes. Eur J App Physiol 11: 2033-2040.

14. Bobovcak M, Kuniakova R, Gabriz J, Majtán J (2010) Effect of pleuran (beta-glucan from Pleurotus ostreatus) supplementation on cellular immune response after intensive exercise in elite athletes. App Physiol Nutr Metabol 35: 755-762.

15. Baddley JW, Winthrop KL, Chen L, Liu L, Grijalva CG, et al. (2014) Non-viral oportunistic infection in new users of tomour necrosis factor inhibitor therapy: results of the SABER study. Ann Rheumatol Dis 73: 1942-1948. 